\title{
HIGH SCHOOL STUDENTS' PERCEPTIONS CASE STUDY: WHAT IS INFORMATION SYSTEMS?
}

\author{
Cherie Noteboom, Dakota State University, Cherie.Noteboom@dsu.edu \\ Kalee Crandall, Dakota State University, Kalee.Crandall@trojans.dsu.edu \\ Kodey S. Crandall, Utah Valley University, kcrandall@uvu.edu \\ Matthew Noteboom, University of Minnesota, Noteb005@umn.edu
}

\begin{abstract}
Although the demand for professionals in the field of Information Systems continues to grow, attracting students into Information Systems programs is a challenge. Today's high school students belong to Gen Z, one of the largest, most educated, and diverse generations. Because this group is just beginning to graduate high school and enter the workforce, understanding what influences their career choices and their perception of Information Systems is of great importance. This research investigates 237 high school students' perceptions of Information Systems. The authors used a qualitative coding process to explain what influences them when considering classes or a career in Information Systems. Five categories emerged from the analysis: Occupation, Ambivalence, Situation, Self-Efficacy and Unspecified/Blank. These findings may provide insight into the career-making processes of current high school students and contribute to meeting the growing market demands for Information Systems professionals by identifying and promoting pathways into the field for a new generation of Information Systems professionals.
\end{abstract}

Keywords: Information Systems, Career Decision-Making, Career Development. OASS-IS, Qualitative

\section{INTRODUCTION}

Our world is characterized by rapid change. The Information Systems (IS) discipline provides the link between the rapidly changing technology landscape and the ways technology transforms individual, organizational and societal practices (Topi, 2017). The Bureau of Labor Statistics indicates that employment of computer and information technology occupations is projected to grow 12\% per year from 2014 to 2024, demonstrating a faster than average growth in the field. These occupations are expected to add approximately 488,500 new jobs, from 3.9 million jobs to about 4.4 million jobs (Occupational Outlook Handbook, 2016). High school students today belong to the second largest generation in American history (Levin, 2019) and are just now beginning to enter the workforce. Understanding the perceptions of this generation regarding the field of information technology is the first step toward meeting labor market demands.

According to the Oxford Dictionary, "perception” is defined as the ability to see, hear, or become aware of something through the senses. An individual's behavior can be unknowingly influenced by knowledge that is formed through their perceptions of reality (Ferguson \& Bargh, 2004). It is only through understanding high school students' perceptions of a career that we can begin to modify behavior, or in this case, increase the number of those entering the field of Information Systems.

Career development theories (A. Bandura et al., 2001; Gottfredson, 1981; Holland, 1997; Lent et al., 2000; Super, 1957) explain how people make occupational choices. Using constructs derived from these theories, this research categorized survey responses of 237 high school students in grades $10,11 \& 12$ to understand their perceptions of Information Systems and what formulates their career choice. Our research used the guiding research question: What perceptions influence a high school student's choice to pursue a career in Information Systems? 


\section{Issues in Information Systems}

Volume 21, Issue 4, pp. 224-233, 2020

\section{LITERATURE REVIEW}

Today's high school students are part of Generation Z, also known as Gen Z, post-Millennials, Gen Z'ers, iGeneration, Gen Tech, Gen Wii, Net Gen, Digital Natives, Gen Next, Post Gen, and Plurals and were born between 1996 and 2010. Comprised of nearly 68 million Americans, this generation is larger than Millennials (born between 1981-1996) and second only to that of the Baby Boomers (born between 1946-1964) (Levin, 2019). This group is typically tech savvy, socially connected to their peers, intelligent, with IQ scores higher than previous generations, generally accepting of diverse populations (Renfro, 2012) and highly value feedback from mentors of their work (Prawitasari, 2018). A Pew Research Center analysis of Census Bureau data found that individuals in Gen $Z$ are enrolling in college at a significantly higher rate than Millennials were at a comparable age, have parents who are more well educated than the parents of those of previous generations, and are just now beginning to enter to labor force (Fry \& Parker, 2018). Early signs indicate that while this generation is on track to become the most well-educated generation, many are entering the labor force much later than previous generations (Fry \& Parker, 2018). Roughly one-in-five 15- to 17year-olds in $2018(19 \%)$ report having worked at all during the prior calendar year. Compared with that, 30\% of Millennial 15- to 17-year-olds worked in 2002. Almost half of early Baby Boomers (48\%) in the same age group worked in 1968 (Fry \& Parker, 2018).

There has been much research on career choices of high school students (Avsec \& Jamšek, 2018; Blackhurst et al., 2003; Buschor et al., 2014; Edwin \& Prescod, 2018; Galliott \& Graham, 2015; Gaylor \& Nicol, 2016; Hijazi et al., 2004; Kim, 2011; Mau \& Bikos, 2000; Theresa, 2015). As Generation Z is now entering the workforce, understanding what influences their career choices is of great importance. It is during this period that students become aware of their interests and abilities and how they are related to work opportunities (Super, 1957) and focus on internal characteristics such as values to guide them in the career decision-making process (Gottfredson, 1981). The different values of each generation can influence an individual's career choice and those who choose careers that match those values will have more satisfaction in their work (Prawitasari, 2018).

The Social Cognitive Career Theory (Lent et al., 2000) integrates elements of previous career theorists, such as Super (1957) and Holland (1997), explains how people develop vocational interests, make occupational choices, and achieve varying levels of career success, while using a perspective based on specific self-efficacy beliefs of each generation. Perceived self-efficacy refers to an individual's beliefs about their abilities to produce effects (Albert Bandura, 1997). Unless people believe they can produce desired outcomes by their actions, they have little incentive to act, or in this case, consider a certain career path. People disregard occupations they believe to be beyond their capabilities, however attractive the occupations may be, which is why perceived self-efficacy is a crucial factor in career choice and development (A. Bandura et al., 2001).

If information about a career is unknown, inaccurate, or unavailable to students, faulty perceptions may also occur. Super (1957) believes that if knowledge of any occupation is inaccurate, that occupation is not going to be well evaluated concerning one's self-concept. Holland's Theory of Vocational Choice (1997) maintains the importance of occupational knowledge and suggests that for an occupational choice to be appropriate, the individual must have accurate occupational knowledge, accurate self-knowledge, and accurate self-evaluation. According to Holland's theory, people who choose to work in an environment similar to their personality type are more likely to be satisfied and successful in their career. This satisfaction will result from individuals being able to express their personalities in supportive environments that include other persons who have the same or similar personality traits (Holland, 1997). Not only does having accurate occupational knowledge increase the likelihood of job satisfaction, but research has also shown that when students have an accurate understanding of the education or other vocational training required for specific occupations, they will have higher occupational aspirations and aspire to greater educational attainment (Mau \& Bikos, 2000). However, if a student fails to develop this accurate knowledge, just the opposite may occur. Having accurate knowledge of an occupation, including educational and vocational training requirements, is essential to the development of realistic, and congruent, educational and occupational aspirations (Theresa, 2015) and can influence perceptions that may prevent students from studying a certain occupation. 
Perception is an individual's construction of his or her reality. For this reason, there is potential for perceptions to be affected by an individual's self-concept, which is the total of all the beliefs people hold about themselves, including

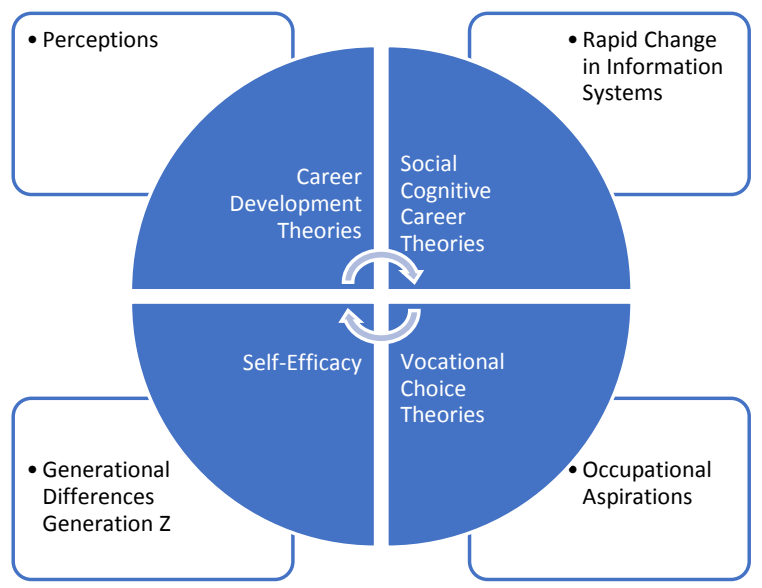

Figure 1: Research Lens personality, interests, and perceived place in society (Gottfredson, 1981). According to Gottfredson's Theory of Circumscription of Compromise (1981), occupational aspirations are a reflection of one's self-concept. People seek occupations that (a) are congruent with their selfimage and (b) reflect their knowledge of different occupations (Figure 1). High school students' perceptions of a career leads them to draw conclusions on which line of work they are best suited for and often causes them to rule out possible careers in which they are only dimly aware (Gottfredson, 2002).

Our research lens is shown in Figure 1 and summarizes our literature review.

More research is needed to understand high school students' perceptions of Information Systems and what barriers influence their career choice formulation. Barriers represent negative outcome expectations related to a career (Swanson et al., 1996) and can be conceived and operationalized as a particular form of outcome expectation related to one's perception of the environment (Lent et al., 2000).

\section{RESEARCH METHODOLOGY}

The investigation of how high school students select their career path is complex and we do not know how students make their career influencing choices to pursue or opt away from Information Systems. Qualitative methods can yield data from which process relationships, models and richer explanations about how and why high school students' choose to pursue a career in Information Systems can be developed (Klein \& Myers, 1999). Qualitative methods provide researchers with the ability to discover relations from data that is systematically gathered and analyzed (Kaplan \& Duchon, 1988). This study uses Eisenhardt's case study approach (1989), utilizes surveys as the primary data collection and open coding for data analysis.

The Eisenhardt method was chosen as it allows the generation of relationships or theories with constant comparison to the literature resulting in a high likelihood of valid relationships and models due to the theory building process being tied to the data and other evidence. Case studies have been used to provide descriptions and generate theories (Lee \& Baskerville, 2003). The goal of this research is to gain a rich description of how and why students' perceptions influence their choice to pursue a career in Information Systems, analyze the data, generate relationships, and construct a model or theory.

The research question, "What perceptions influence a high school student's choice to pursue a career in Information Systems?" was explored using demographic and open-ended questions. This method was applied in the collection of data from the field to provide insight into the career-making processes of secondary students regarding Information Systems.

The case study is well matched to the open coding analysis as it is "highly iterative and tightly linked to the data" (Eisenhardt, 1989, p. 532). Open coding is used to analyze the data and develop concepts as they relate to high school students' choice to pursue a career in Information Systems. The combination enables concepts and relationships to be arrived at and then assessed using the enfolding literature from Eisenhardt and theoretical sensitivity from open coding. Theoretical sensitivity allows the researchers to have insight and to give meaning to the happenings in the data. It allows being able to see beneath the obvious to discover the new. "Insights do just not occur haphazardly; rather, they happen to prepared minds during interplay with the data” (Strauss \& Corbin, 1998a, p. 47). 


\section{DATA COLLECTION}

\section{Study Participants}

The target population for this study was high school students at a secondary public school in the Mountain Region in the United States. Of the two hundred and thirty-seven participants, 82 students were in $10^{\text {th }}$ grade, 76 students in $11^{\text {th }}$ grade, and 79 in $12^{\text {th }}$ grade. There were 109 male and 128 female students who completed surveys, as shown in Table 1 . The sample population also consisted of students who had nearly $90 \%$ of their parents completing at least one year of college, and almost $81 \%$ having four years of college or beyond. The online survey was administered between February 2019 and March 2019 in a computer lab during regular school hours with assistance from school counselors.

Table 1: Sample population demographics by grade and gender

\begin{tabular}{|l|l|l|}
\hline & Male & Female \\
\hline 10 th Grade & 41 & 41 \\
\hline 11 th Grade & 35 & 41 \\
\hline 12 th Grade & 33 & 46 \\
\hline
\end{tabular}

\section{DATA ANALYSIS}

While analyzing the transcripts of the surveys, "labels of meaning” were identified and placed next to the relevant occurrence. Occurrences were events, happenings, actions, feelings, perspectives, and interactions. Categorization of the coding was done in two phases. First, the data obtained from the interviews was coded into broad categories. The interview data was analyzed using Strauss \& Corbin's (1998) open coding method by two sets of coders. Open coding was used to conceptualize raw data by naming and categorizing the phenomena through close examination of the data. During open coding, data was broken down into discrete parts, closely examined and compared for similarities and differences. The coding process yielded 476 instances. The data representing events, happenings, actions, feelings, perspectives and interactions that were found to be conceptually similar in nature or related in meaning were grouped under abstract concepts that best represent the phenomenon. According to Strauss and Corbin (1998), although events or happenings might be discrete elements, the fact that they share common characteristics or related meanings enables them to be grouped. Based on their ability to explain what is going on, certain concepts were grouped under more abstract higher order concepts which Strauss and Corbin (1998) term as categories. Categories have analytic power because they can have the potential to explain why students may or may not choose career paths and predict the effects of choices. The 476 instances were categorized to compare codes across the survey responses. The categories were derived by tabulating the number of occurrences of related concepts.

Reliability of these groupings was achieved through theoretical sensitivity, iterative coding and theoretical sampling. Strauss and Corbin (1998) suggest that theoretical sensitivity is required to enable the researcher to interpret and define data and thus develop relationships, models or theories that are grounded, conceptually dense and wellintegrated. Sources of theoretical sensitivity are the literature, professional experiences and personal experiences. Additional reliability was achieved through the iterative use of open and axial coding to bring out the concepts and discover any causal relationships or patterns in the data. Strauss and Corbin state that "though open and axial coding are distinct procedures, when the researcher is actually engaged in the analysis he or she alternates between the two modes" (1998b, p. 98).

As shown in Table 2: Identified Categories and Kappa, the data analysis identified five categories: 1) Occupation, 2) Ambivalence, 3) Situation, 4) Self-Efficacy, 5) Unspecified/Blank. 
Volume 21, Issue 4, pp. 224-233, 2020

Table 2: Identified Categories and Kappa

\begin{tabular}{|l|l|l|}
\hline Category Name & Instances & Kappa \\
\hline Occupational & 227 & .93 \\
\hline Ambivalence & 100 & .83 \\
\hline Situational & 85 & .86 \\
\hline Self-Efficacy & 32 & .76 \\
\hline Unspecified/Blank & 32 & .81 \\
\hline
\end{tabular}

High school students' perceptions influence future career paths and understanding these perceptions, rather than object reality, is of fundamental importance. The categories identified in the coding process provide insight into the perceptions of high school students regarding training and careers in Information Systems.

\section{RESULTS}

In Figure 2, we present the IS Career Choice Model OASS-IS (Occupation, Ambivalence, Self-Efficacy and Situation - Information Systems) which illustrates how high school student perceptions influence the pursuit of Information Systems career paths. Following the model, a detailed explanation of each category and instances are provided.

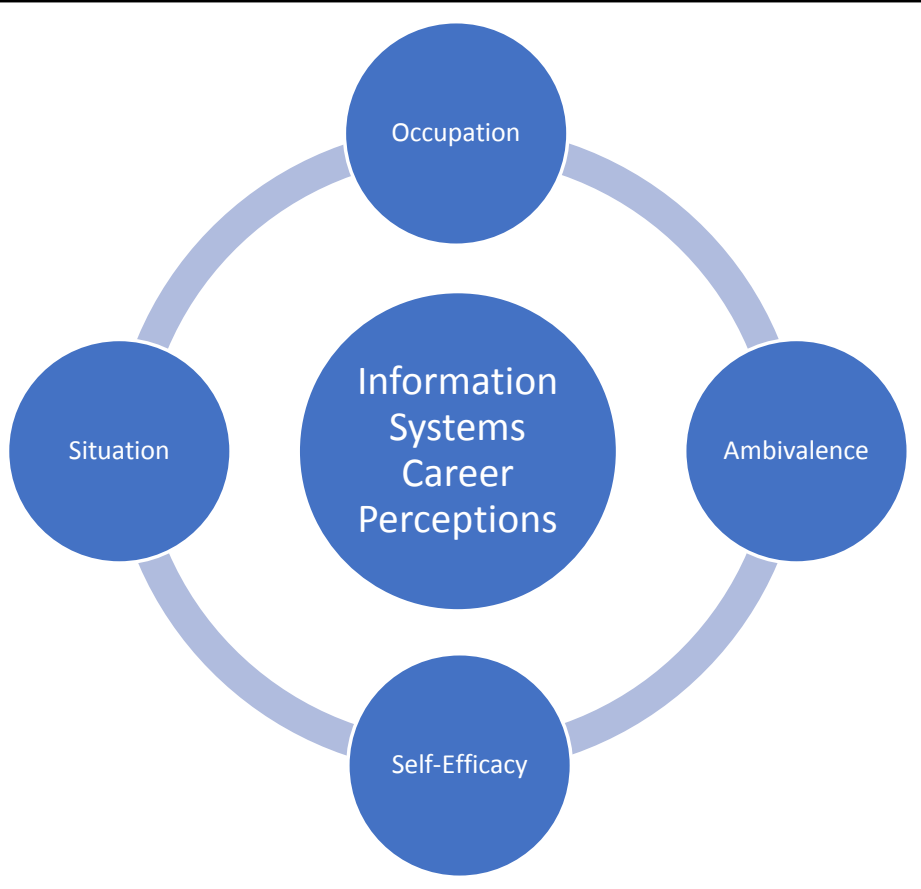

Figure 2: IS Career Choice Model OASS-IS

\section{Occupation}

According to Gottfredson (1981), people seek occupations that are congruent with their self-image and reflect their knowledge of different occupations. Responses in this category included students who said they were interested in an alternative occupation, did not know what would prevent them from pursuing training or a career in IS, said nothing would prevent them from entering the field of IS, or had no occupational knowledge of the field. There were 227 coded instances and $47.7 \%$ that fit into this category. 
"I really just enjoy doing creative things and putting myself out in the world, and that career doesn't seem like it would follow that." "Not applicable for my career path", "I am more interested in global studies than Information Systems, despite having extensively explored it." "Simply interested in something else", "I want to work with people", "I can't sit in a desk all day", "I don't know", "Nothing”, "Not sure", "Nothing would prevent me besides myself", "I'm not even sure what information systems is", "I don't know what that is", "What is Information Systems?", "Don't know anything about it".

\section{Ambivalence}

Ambivalence refers to having mixed feelings or contradictory ideas about something (Lexico, 2020). In career exploration, particularly in adolescence, ambivalence towards choosing a career seems to be a growing trend. The results of our survey confirm this supposition as there were 100 instances, or 1 out of 5 students, who had a response that fit within this category. Students who responded with the words like, "uninterested" or "I really don't have any interest" or "boring" fit within this category.

"Not interested”, “Doesn't interest me”, "It doesn't interest me”. "I really don't have any interest”, "Boring”, "It sounds boring", "I have a hard time not immediately labeling it as boring".

\section{Situation}

Situational barriers are obstacles related to one's job, family, age, or economic circumstances (Mertesdorf, 1990). For example, one may not choose a career path because the academic requirements are not available at the school he or she is attending. Another may not have access to the support or resources needed to make a decision. These unique situations were shown to influence the perceptions of high school students pursuing training a career in IS. There were 85 instances (17.9\% of students) who reported some type of situational barrier.

"Having a family or going on a mission", "Credits I need," "Not enough elective space," "The only thing that would prevent me is if there was no room in my schedule", "Past experiences", "Stress", "Physical limitations", "Cost", "Money for college", "finances," "Because of money and my limited knowledge of scholarships available and how to apply to universities etc."

\section{Self-Efficacy}

Self-Efficacy is based on the perception that the student would not be successful in the career due to some internal characteristic. In other words, a student perceives the occupation requires skills beyond his or her capabilities (A. Bandura et al., 2001). Our Self-Efficacy category had 32 coded instances (6.7\%) and included responses where students indicated inability due to skills, motivation or ability to succeed.

"Not wanting to take the class", "Doubting my abilities", "Not good with tech", "inability", "difficulty", "If the teacher is hard then I will not do it".

\section{Unspecified/Blank}

There were 32 (6.7\%) coded instances where there was either not enough information to determine the code, the information was irrelevant to the question or students did not answer the question. These instances comprise the Unspecified/Blank category and were removed from further analysis.

\section{DISCUSSION \& RECOMMENDATIONS}

The OASS-IS model with Occupation, Ambivalence, Self-Efficacy and Situation categories influencing Information Systems Career Perceptions contributes to understanding the unique perceptions high school students have regarding Information Systems career opportunities. Based on these findings, we recommend focusing on these categories and their interaction on career choice to increase high school students' occupational knowledge of Information Systems and help them identify and develop the necessary skills, abilities, and self-efficacy needed to be successful in the field. 
Many students in this research appeared to be unaware of the career paths in the field of Information Systems. In the Occupation category, the analysis indicates alternate career path selection, consideration of Information Systems Career path and ignorance of the Information Systems field. There may be an opportunity to clarify their understanding of the work context and to improve students' occupational knowledge of the field. Students' perceptions of Information Systems being “dull” or "boring” may stem from a misunderstanding of the field or ambivalence. Research has shown ambivalence in adolescence is a temporary state and may be overcome through targeted interventions (Kasperzack et al., 2014).

Information Systems advocates may attempt to overcome the perceptions of ambivalence or lack of knowledge of Information Systems occupation by engaging students using challenges such as Twitter feed data analysis competitions, virtual scavenger hunts, or security camps. Activities such as these not only generate interest but can also help students gain a better understanding of the field.

A large proportion of students in this study stated "cost" as a barrier to the training needed to pursue a career in Information Systems. While the cost of post-secondary training continues to rise, research has shown most high school students are unaware of the actual price of college and most tend to overestimate rather than underestimate prices (Source). Financial aid is available to help students from all backgrounds. These packages include federal grants, government and private loans, scholarships, and institutional aid. High school students should be encouraged to apply for financial assistance early and seek support from guidance counselors for help throughout the process.

Another critical barrier limiting students who enter the field of Information Systems is self-efficacy, or their perceived ability to be successful in the field. Mentors are crucial in helping to accurately persuade an adolescent that they have the ability to succeed.

The OASS-IS model implies students move through Occupation, Ambivalence, Self-Efficacy and Situation influenced phases as they consider their career paths. Awareness of the transition students make enables interventions to provide supporting activities and knowledge regarding career choice. The potential to assist Generation $\mathrm{Z}$ to discover the career paths to success in Information Systems or their alternate career is defined in our model.

Future research could refine these categories by exploring them in more depth to discover solutions to students' perceptions of the field of Information Systems. Another relevant and interesting direction for future research should investigate the differences in male and female perceptions of Information Systems. Our next steps may further investigate our gender results. The allocation of our category instances by gender are shown in Figure 3. 


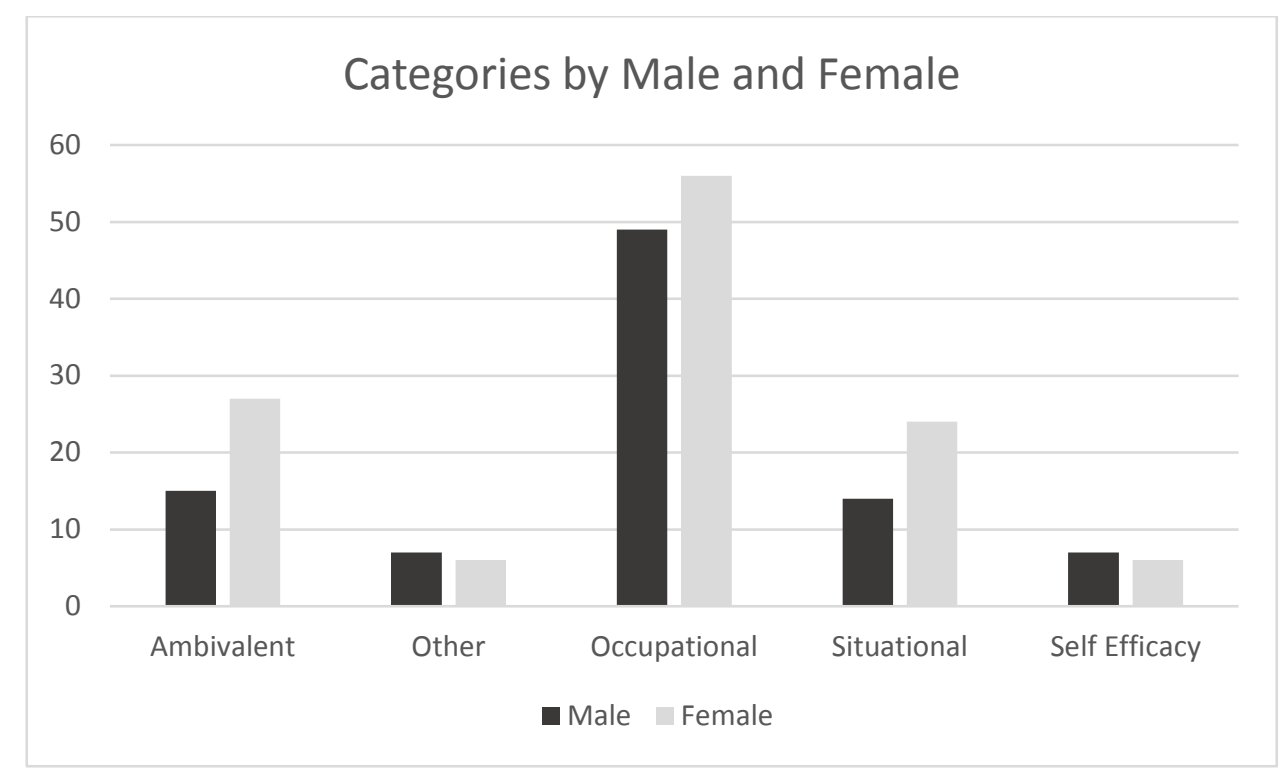

Figure 3: Category Instances by Gender

\section{CONCLUSION}

Our research utilized a qualitative design to investigate the research question, What perceptions influence a high school student's choice to pursue a career in Information Systems? The categories discovered and the model presented illustrate the perceptions and relationships influencing high school students as they evaluate an Information System career. The OAIS-IS Model provides insight for educators, career counselors and practice to engage the next generation of Information Systems professionals.

Our results indicate a perception of limited recognition of the Information Systems career path and a perception of the filed of Information Systems as uninteresting or boring for high school students. The profession may be challenged to attract these students into Information Systems programs and ultimately to the growing number of professional positions in the field. As a profession, Information Systems needs to investigate and explore opportunities to improve its relevance to this age group as they select their career paths and transition into the work force.

It is an important area of study to provide insights for attracting students to the possibilities available in the Information Systems career area, match appropriate students to engaging career paths and meet the growing employment opportunities in the field. Discovering and understanding student perspectives is an important step towards integrating a new generation of professionals into the field of Information Systems. As Simon (1982, p. 162) said, "Learning results from what the student does and thinks, and only from what the student does and thinks. The teacher can advance learning only by influencing the student to learn."

This research is limited as it represents a single case study on one high school as described in the data collection section. Future research should investigate high schools with varying demographics and increased diversity. This would improve the generalizability of the effort. In addition, future research has potential to be expanded to perspectives of college students and early career IS professionals. There is an opportunity to improving the data collection methods to obtain richer data or designing a quantitative research method. Further research is necessary to explore the area of perceptions of Information Systems and improve the field. 


\section{REFERENCES}

Avsec, S., \& Jamšek, J. (2018). A path model of factors affecting secondary school students' technological literacy. Int J Technol Des Educ, 28(1), 145-168. doi:10.1007/s10798-016-9382-z

Bandura, A. (1997). Self-Efficacy: The Exercise of Control (Vol. 1): Worth Publishers.

Bandura, A., Barbaranelli, C., Caprara, G. V., \& Pastorelli, C. (2001). Self-efficacy beliefs as shapers of children's aspirations and career trajectories. Child development, 72(1), 187.

Blackhurst, A. E., Auger, R. W., \& Wahl, K. H. (2003). Children's Perceptions of Vocational Preparation Requirements. Professional School Counseling, 7(2), 58-67.

Buschor, C., Kappler, C., Frei, A., \& Berweger, S. (2014). I want to be a scientist/a teacher: students' perceptions of career decision-making in gender-typed, non-traditional areas of work. Gender and Education, 26(7), 743. doi:10.1080/09540253.2014.970615

Edwin, M., \& Prescod, D. (2018). Fostering Elementary Career Exploration with an Interactive, Technology-Based Career Development Unit. Journal of School Counseling, 16(13), 29.

Eisenhardt, K. M. (1989). Building theories from case study research. Academy of Management Review,, 14(4), 532550.

Ferguson, M. J., \& Bargh, J. A. (2004). How social perception can automatically influence behavior. Trends in Cognitive Sciences, 8(1), 33-39. doi:10.1016/j.tics.2003.11.004

Fry, R., \& Parker, K. (2018). Early Benchmarks Show ‘Post-Millennials’ on Track to Be Most Diverse, Best-Educated Generation Yet. A demographic portrait of today's 6- to 21-year-olds. Retrieved from https://www.pewsocialtrends.org/2018/11/15/early-benchmarks-show-post-millennials-on-track-to-bemost-diverse-best-educated-generation-yet/

Galliott, N. y., \& Graham, L. (2015). School based experiences as contributors to career decision-making: findings from a cross-sectional survey of high-school students. Aust. Educ. Res., 42(2), 179-199. doi:10.1007/s13384015-0175-2

Gaylor, L., \& Nicol, J. (2016). Experiential High School Career Education, Self-Efficacy, and Motivation. Canadian Journal of Education, 39(2), 1-24.

Gottfredson, L. S. (1981). Circumscription and compromise: A developmental theory of occupational aspirations. Journal of Counseling Psycology, 28, 545-579.

Gottfredson, L. S. (2002). Gottfredson's Theory of Circumscription, Compromise, and Self-Creation. San Francisco, CA: Jossey-Bass.

Hijazi, Y., Tatar, M., \& Gati, I. (2004). Career Decision-Making Difficulties Among Israeli and Palestinian Arab High-School Seniors. Professional School Counseling, 8(1), 64-72.

Holland, J. L. (1997). Making vocational choices: A theory of vocational personalities and work environments (Vol. 3). Odessa FL.

Kaplan, B., \& Duchon, D. (1988). Combining Qualitative and Quantitative Methods in Information Systems Research: A Case Study. MIS Quarterly, 12, 571-586. doi:10.2307/249133 
Kasperzack, D., Ernst, A. L., \& Pinquart, M. (2014). Ambivalence During and After Career Decision Making of High School Graduates. Journal of Career Assessment, 22(2), 248-260.

Kim, M. (2011). The Relationship Between Thinking Style Differences and Career Choices for High-Achieving Students. Roeper Review, 33(4), 252-262. doi:10.1080/02783193.2011.603113

Klein, H., \& Myers, M. (1999). A set of principles for conducting and evaluating interpretive field studies in information systems. MIS Quarterly, 23(1), 67-93. doi:10.2307/249410

Lee, A. S., \& Baskerville, R. L. (2003). Generalizing Generalizability in Information Systems Research. Information Systems Research, 14(3), 221-243.

Lent, R. W., Brown, S. D., \& Hackett, G. (2000). Contextual Supports and Barriers to Career Choice: A Social Cognitive Analysis. Journal of Counseling Psychology, 47(1), 36.

Levin, D. (2019). Generation Z: Who They Are, in Their Own Words. Retrieved from https://www.nytimes.com/2019/03/28/us/gen-z-in-their-words.html

Lexico. (2020). Definition of Ambivalence.

Mau, W.-C., \& Bikos, L. H. (2000). Educational and Vocational Aspirations of Minority and Female Students: A Longitudinal Study. Journal of Counseling \& Development, 78(2), 186-194. doi:10.1002/j.15566676.2000.tb02577.x

Mertesdorf, J. (1990). Learning styles and barriers to learning perceived by adult students on campus. In J. P. Wilson (Ed.): ProQuest Dissertations Publishing.

Occupational Outlook Handbook. (2016). Washington, DC: U.S. Bureau of Labor Statistics Retrieved from http://www.bls.gov/ooh/computer-and-information-technology/home.htm

Prawitasari, G. (2018). The Influence of Generations on Career Choice (Social Cognitive Career Theory Perspective). Konselor, 7. doi:10.24036/02018718464-0-00

Renfro, A. (2012). Meet Generation Z. Retrieved from https://www.gettingsmart.com/2012/12/meet-generation-z/

Simon, H. A. (1982). Models of bounded rationality. Volume 3: Cambridge, Massachusetts : The MIT Press.

Strauss, A., \& Corbin, J. M. (1998a). Basics of qualitative research: Grounded theory procedures and techniques (2nd ed.). Thousand Oaks: US: Sage Publications, Inc.

Strauss, A., \& Corbin, J. M. (1998b). Basics of qualitative research: Grounded theory procedures and techniques (2nd ed.). Thousand Oaks: US: Sage Publications, Inc.

Super, D. (1957). The Psychology of Careers. New York: Harper \& Row.

Swanson, J. L., Daniels, K. K., \& Tokar, D. M. (1996). Assessing perceptions of career-related barriers: The Career Barriers Inventory. Journal of Career Assessment, 4, 219-244.

Theresa, L. D. (2015). Factors that Inform Students' Choice of Study and Career. Journal of Education and Practice, 6(27), 43-49.

Topi, H. (2017). IS EDUCATIONRole of information systems in the CC2020 initiative. ACM Inroads, 8(4), 43-44. doi:10.1145/3148549 